Vol. 2 No. 2 Juli 2019

ISSN 2614-2775

e-ISSN 2621-8143
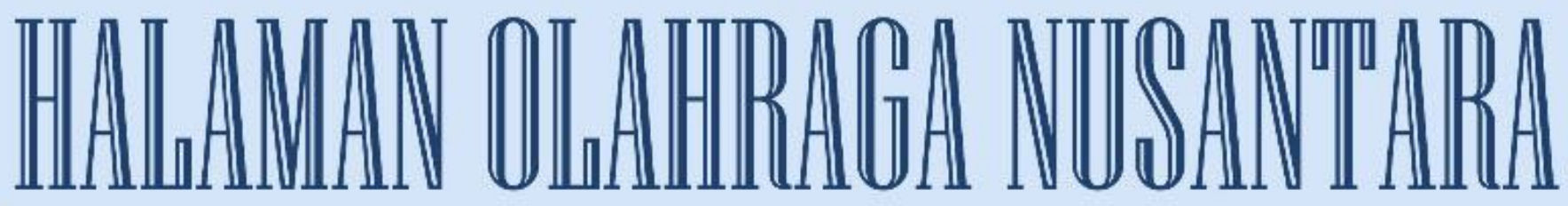

Surnal @lmu Xeolahragaan

Diterbitkan Oleh:

Program Studi Pendidikan Olahraga

Fakultas Keguruan dan Ilmu Pendidikan

Universitas PGRI Palembang

\begin{tabular}{|c|c|c|c|c|c|}
\hline Jurnal & Volume & Nomor & Halaman & Palembang & ISSN/e-ISSN \\
\hline IIalaman Oahrayg Ninsantarata & 2 & 2 & $97-197$ & 2019 & $\begin{array}{c}2614-2775 / \\
2621-8143\end{array}$ \\
\hline
\end{tabular}


Halaman Olahraga Nusantara (Jurnal Ilmu Keolahragaan)

P-ISSN 2614-2775

Volume 2, No. 2, Januari 2019

E-ISSN 2621-8143

\section{DAFTAR ISI}

Hasil Penelitian

Halaman

Penerapan Model Permainan Rounders Yang Dimodifikasi Terhadap Kemampuan Gerak Dasar Murid Sd Negeri Paccinongan Kabupaten Gowa

- Benny B, M.Rachmat Kasmad

Pelaksanaan Kegiatan Belajar Mengajar Pendidikan Jasmani di Sekolah Dasar Inklusi

- Bambang Gatot Sugiarto

Pengaruh Metode Latihan Terhadap Daya Tahan Fisik Siswa Ekstrakurikuler Sepak Bola Sma N 2 Tanjung Raja

- Mutiara Fajar.

Survei Minat Member Yang Mengikuti Fitness Pada Pusat Kebugaran Kota Palembang

- Hengki Kumbara.

Peningkatan Pengaruh Latihan Kelincahan Terhadap Kemampuan Menggiring Bola Pada Siswa Sma Negeri 3 Samarinda

- Ruslan, Nurjamal

Penerapan Permainan Dengnan Media Swiss Ball Untuk Meningkatkan Kelentukan Lower Back (Pada Mahasiswa Kop Aerobic Gymnastics Universitas Negeri Jakarta)

- M Dian Susanto, Sri Nuraini $141-153$

Patrol Multiguna Sebagai Alternatif Media Pembelajaran Tolak Peluru Di Smp Negeri 1 Sei Balai Kabupaten Batu Bara Tahun Ajaran 2017/2018

- Joko Priono $154-166$ 
Kecerdasan Gerak Dalam Pendidikan Jasmani

- Hilda Oktriyeni....................................................................... 167-176

Analisis Kesalahan Tendangan Atlet Pencak Silat Universitas PGRI Palembang

- Bayu Iswana............................................................................ 177-185

Pengaruh Metode Pembelajaran Dan Kriteria Layanan Bantuan:

Meningkatkan Gerak Dasar Lompat Jauh Gaya Jongkok Siswa Tunagrahita Ringan Pada Pembelajaran Penjasorkes SLB PKK Bandar Lampung

- Rachmi Marsheilla Aguss.............................................................. 186-197 


\title{
PENGARUH METODE PEMBELAJARAN DAN KRITERIA LAYANAN BANTUAN: MENINGKATKAN GERAK DASAR LOMPAT JAUH GAYA JONGKOK SISWA TUNAGRAHITA RINGAN PADA PEMBELAJARAN PENJASORKES SLB PKK BANDAR LAMPUNG
}

\author{
Oleh : Rachmi Marsheilla Aguss \\ (Universitas Teknokrat Indonesia)
}

\begin{abstract}
Abstrak
Penelitian ini bertujuan mengetahui perbedaan pengaruh antara metodebermain dan metode konvensionaluntuk meningkatkan gerak dasar lompat jauh gaya jongkok, perbedaan pengaruh kriteria bantuan mandiri dan kriteria minimal untuk meningkatkan gerak dasar lompat jauh gaya jongkok siswa tunagrahita ringan, dan interaksi antara metodepembelajaran dan kriteria layanan bantuan untuk meningkatkan gerak dasar lompat jauh gaya jongkok siswa tunagrahita ringan.Penelitian eksperimen ini faktorial 2x2.Populasi 20siswa kelas IV SLB PKK Bandar Lampung.Sampel 20siswa dibagi menjadi 4 kelompok, setiap kelompok terdiri dari 5 siswa, pengambilan sampel dengan total sampling.Analisis data digunakan uji Anava dua arah taraf signifikansi 5\%, dilanjutkan uji Tukey. Hasil penelitian: (1) adaperbedaan pengaruh antara metode bermain dan metode konvensional $F_{h i t}(6,095)>F_{\text {tab }}(3,24) ;(2)$ ada perbedaan pengaruh antara kriteria bantuan mandiri dan kriteria bantuan minimalF $_{\text {hit }}(4,667) \quad>F_{\text {tab }}(3,24) ; \quad$ (3) terdapat interaksi antara metodepembelajarandan kriteria layanan bantuan untuk meningkatkan gerak dasar lompat jauh gaya jongkokF $F_{h i t}(6,095)>F_{\text {tab }}(3,24)$.Simpulan:(1) metode bermain memberikan pengaruh yang signifikan dibandingkan dengan metode konvensional; (2) siswa dengan kriteria bantuan mandiri memberikan pengaruh yang signifikan untuk meningkatkan gerak dasar lompat jauh gaya jongkok siswa tunagrhaita ringan; (3) terdapat interaksi antara metode pembelajaran dan kriteria layanan bantuan. Saran bagi guru penjasorkes untuk meningkatkan gerak dasar lompat jauh gaya jongkok, lebih memilih metodebermain, mengembangkan metodebermain, dan perlu memperhatikan kriteria layanan bantuan pada masingmasing anak.
\end{abstract}

Kata kunci :Metode Belajar, Lompat Jauh, Tuna Grahita

\section{THE EFFECT OF LEARNING METHODS AND AID SERVICES CRITERIA TO IMPROVE BASIC MOTION LONG JUMP SQUATTING STYLE MILD MENTAL RETARDATION STUDENT IN PHYSICAL EDUCATION LEARNING OF SLB PKK BANDAR LAMPUNG}

\footnotetext{
Abstract

This study aims to determine the differences in influence between play methods and conventional methods to improve the basic motion of squat style long jumps, differences in the influence of self-help criteria and minimum criteria to improve the basic motion of long jump squatting styles of mild mental retardation
} 
students, and interaction between learning methods and criteria for aid services to improve motion the basis of the long jump squatting style of mild mental retardation students. The experimental study was factorial $2 \times 2$. The population of 20 students in the IV class of the Bandar Lampung PKK SLB. The sample of 20 students was divided into 4 groups, each group consisted of 5 students, sampling with total sampling. direction of the significance level of 5\%, followed by the Tukey test. The results of the study: (1) there were differences in influence between the playing method and the conventional method of Profit (6.095)> Ftab (3.24); (2) there were differences in influence between the criteria for independent assistance and the minimum criteria of assistance (4.667) (3) there is an interaction between learning methods and the criteria of aid services to improve the basic motion of squat-style long jump (6.095)> Ftab (3.24). Conclusions: (1) play method has a significant effect compared to conventional methods; (2) students with independent help criteria have a significant influence to improve the basic motion of the long jump squatting style of mild tunagrhaita students; (3) there are interactions between learning methods and criteria for assistance services. Suggestions for penjasorkes teachers to improve the basic movements of squat style long jumps, prefer playing methods, develop playing methods, and need to pay attention to the help service criteria for each child.

Key Words :Learning Methdos, Long Jump, Mental Reserdation

\section{A. PENDAHULUAN}

Pendidikan jasmani, olahraga dan kesehatan merupakan bagian integral dari sisem pendidikan.Pendidikan jasmani juga memiliki peran sentral pada SLB.Konteks belajar pendidikan jasmani menjadi tanggung jawab guru penjasorkes di sekolah dan dilaksanakan bersamaan dengan kegiatan belajar mengajar.Tujuan pembelajaran penjasorkes anak berkebutuhan khusus, merefleksikan kebutuhan dalam membantu individu mengembangkan diri secara optimal sesuai dengan tahap perkembangan dan predisposisi yang dimiliki meliputi kemampuan bakat, minat, permasalahn, dan kebutuhannya serta sesuai dengan latar belakang sosial budaya dan tuntutan positif lingkungan (Sunardi, 2005).

Pendidikan luar biasa, sebagai salah satu bentuk pendidikan yang khusus mengenai anak-anak berkelainan sebagai objek formal dan materialnya dari berbagai jenis kelainan, termasuk anak-anak tunagrahita, secara terus-menerus berupaya untuk meningkatkan pelayanan dengan sebaik-baiknya. Bagaimanaun, 
warga negara anak-anak tunagrahita memiliki hak yang sama untuk mendapatkan pendidikan. Pasal 5 Undang-Undang Nomor 2 Tahun 1989 tentang sistem pendidikan nasional, menyatakan bahwa setiap warga mempunya hak yang sama untuk memperoleh pendidikan, nyang di antara nya adalah anak-anak tunagrahia (Nunung, 2014).

Penyampaian materi pembelajaran agar dapat berlangsung efisien dan efektif diperlukan metode pembelajaran. Cara-cara yang dilakukan guru dalam melaksanakan tugas pembelajaran sering berganti istilah mulai dari strategi mengajar, gaya mengajar sampai metode pembelajaran. Namun pada prinsipnya pemakaian dari ketiga istilah tersebut adalah mempunyai arti yang sama yaitu siasat guru menggiatkan partisipasi siswa untuk melaksanakan tugas-tugas ajar (Lutan, 2000).

Lompat jauh adalah nomor yang paling sederhana dan paling sederhana dibandingkan nomor-nomor lapangan lainnya(Eddy, 2011). Hal ini dikarenanakan para siswa sebelum diberikan pembelajaran atau latihan lompat jauh siswa sudah dapat melakukan gerak dasar lompat jauh, hal ini akan mengakibatkan para siswa akan cepat mempelajari lompat jauh dengan benar. Teknik lompat jauh sedikit terjadi perubahan selama masa dasawarsa dan pada awal abad ke 20 para pelompat telah menggunakan gaya jongkok atau sail style yang murni dan juga berbagai macam gaya dalam lompat jauh seperti gaya menggantung dan gaya berjalan di udara masih terlihat sampai sekarang.

Survey dilakukan di SLB PKK Bandar Lampung terhadap proses pembelajaran penjasorkes materi lompat jauh yang dilakukan siswa kelas IV dan menemukan permasalahan dalam proses pembelajaran lompat jauh gaya jongkok.Berdasarkan hasil wawancara guru penjasorkes SLB PKK Bandar Lampung, bahwa di SLB PKK Bandar Lampungmasih menggunakan metode pembelajaran seperti di sekolah-sekolah pada umumnya. Dalam proses belajar mengajar penerapan metode yang digunakan cenderung monoton dan belum adanya inovasi yang dilakukan oleh guru dalam proses belajar mengajar.

Hasil observasi, 94 jumlah siswa pada SLB PKK Sukarame Bandar Lampung untuk kelas tunagrahita ringan terdapat didalamnya 6 anak autistik yang 
digabungkan menjadi satu. Pada 94 anak tunagrahita SLB PKK Sukarame Bandar Lampung diperoleh data dari kelas IV sebanyak3 kelas sebesar $64,06 \%$ rata-rata anak tunagrahita ringan berkategori baik, dengan rincian kategori hasil belajar dan pembelajaran penjasorkes khususnya materi lompat jauh sebagai berikut: kategori baik sekali (BS) sebanyak 2 orang, kategori baik (B) sebanyak 9 orang, kategori cukup baik (CB) sebanyak 4 orang, kategori kurang baik sebanyak 5 orang. Dari data tersebut menunjukkan bahwa perkembangan hasil belajarcukup baik, namun demikian perlu dikaji dan dilihat dari kategori cukup baik dan kurang baik untuk ditingkatkan hasil pembelajaran penjasorkes khususnya materi lompat jauh.

Metode pembelajaran dengan menggunakaan metode bermain tidak pernah diterapkan oleh guru mata pelajaran penjasorkes. Metode pembelajaran yang digunakan oleh guru cenderung menggunakan metode lama yang biasa diterapkan di sekolah-sekolah pada umumnya. Dalam pembelajaran atletik berfokus pada penguasaan teknik dan berorientasi kepada hasil siswa pada setiap nomor atletik.Pada materi atletik khususnya pembelajaran lompat jauh gaya jongkok jarang sekali diajarkan oleh guru yang dikarenakan keadaan siswa yang tidak memilki kemauan saat pembelajaran tersebut.Pada pembelajaran atletik, gerakgerak dasar tidak pernah diberikan oleh guru mata pelajaran tersebut.Kurikulum yang digunakan di SLB PKK masih menggunakan kurikulum yang sama dengan sekolah umum dimana siswa-siswinya berbeda dengan anak luar biasa.

Unsur bermain dan kesenangan siswa berarti kurang diperhatikan. Kemampuan guru penjas dalam menyajikan proses belajar mengajar atletik yang lebih banyak menekankan pada penguasaan teknik dan berorientasi kepada hasil. Dari segi materi yang diajarkan saat pembelajaran sama seperti anak sekolah umum. Tidak adanya pembagian antara materi pelajaran umum dan materi pelajaran khusus.Hal ini menyebabkan bahwa anak tunagrahita ringan sulit memahami materi yang diajarkan, termasuk pada pembelajaran lompat jauh gaya jongkok pada materi atletik. Siswa tunagrahita ringanmasih sulit untuk bisa melaksanakan lompat jauh dengan teknik gaya jongkok. Pada lompat jauh gaya jongkok rata-rata siswa hanya bisa melakukan lompatan dengan sangat sederhana atau melompat hanya sekedar melompat. 
Penyandang tunagrahita juga merupakan bagian dari manusia, tetapi anak tunagrahita belum menikmati kelebihan yang sedikit banyak sama apa yang anakanak normal miliki. Lewat jalur pendidikan luar biasalah anak-anak tunagrahita bisa mengembangkan potensi diri dan pengetahuan. Materi atletik lompat jauh gaya jongkok yang berisi dengan gerak-gerak dasar jalan, lari, lompat, dan lempar sangat cocok untuk membantu para siswa SLB dalam upaya meningkatkan kemampuan geraknya.

Identifikasi masalah sesuai dengan latar belakang masalah di atas adalah sebagai berikut.Gurubelum melakukan inovasi pembelajaran pada mata pembelajaran penjasorkes untuk materi lompat jauh gaya jongkok, kurangnya keaktifan siswa dapat berpengaruh terhadap hasil pembelajaran, Pengaruhmetode pembelajaran untuk anak tunagrahita ringan dalam pembelajaran penjasokes, belum adanya kriteria layanan bantuan yaitu bantuan mandiri, minimal, dan maksimal oleh guru.

Rumusan Masalah: (1) Apakah ada perbedaan pengaruh antara metode bermain dan metode konvensional untuk meningkatkan gerak dasar lompat jauh gaya jongkok siswa tunagrahita ringan? (2) Apakah ada perbedaan kriteria layanan bantuan mandiri dan layanan bantuan minimal? (3) Apakah ada interaksi antara metode pembelajaran dan kriteria layanan bantuan untuk meningkatkan gerak dasar lompat jauh gaya jongkok siswa tunagrahita ringan?

Husdarta dan Yudha M. Saputra (2000) mendefinisikan metode pembelajaran merupakan cara guru bertinteraksi dengan siswa agar tujuan pembelajaran dapat dicapai. Sedangkan Adang Suherman dan Agus Mahendra (2001) menyatakan bahwa metode pembelajaran merupakan keseluruhan cara atau teknik dalam menyajikan bahan pembelajaran kepada siswa, serta bagaimana siswa diperlakukan selama pembelajaran.

Metode pembelajaran didefinisikan sebagai cara-cara untuk mencapai hasil pembelajaran dan digunakan dalam kondisi tertentu untuk mencapai hasil pembelajaran yang diinginkan. Cara ini disebut strategi pembelajaran. Metode yang bervariasi atau strategi pembelajaran hal yang paling esensial dalam proses pembelajaran. Kondisi dan tujuan yang bervariasi merupakan variabel yang tidak 
bisa di ubah dan merupakan landasan dalam proses pembelajaran. Adapun peluangnya memanipulasi metode pembelajaran yang bervariasi untuk mencapai hasil pembelajaran yang diinginkan (Depdiknas, 2007).

Djamarah (2006) mengatakan bahwa metode pembelajaran konvensional adalah metode pembelajaran tradisional atau disebut juga dengan metode ceramah atau metode komando karena sejak dulu metode ini telah digunakan sebagai alat komunikasi lisan antara guru dengan anak didik dalam proses belajar dan pembelajaran

Sukintaka (1997) mengatakan bahwa bermain dapat dirumuskan sebagai aktivitas jasmani yang dilakukan sukarela dan bersungguh-sungguh untuk memperoleh rasa senang dari melakukan aktivitas tersebut. Untuk bermain baim anak-anak maupun dewasa pasti mereka membutuhkan teman bermain, sebab pada dasarnya mereka bermain berawal dari naluri bergeraknya dan terdorong baik untuk memenuhi kebutuhan isyarat-isyarat dari dorongan. Dimana anak-anak bermain tanpa memikirkan akan tujuan dari permainan mereka.

Sukintaka (1997) mengatakan bahwa bermain lebih tua dari kebudayaan, sebab kebudayaan itu didasari oleh pemikiran dan segala peristiwa antar manusia.Manusia bermain untuk mendapatkan kesenangan, kegembiraan, dan kenikmatan. Sehingga akan ada unsur sukarela, dan akan berprilaku jujur serta tidak akan melukai teman bermainnya karena keinginan untuk memperoleh kesenangan bersama. Manusia bermain juga untuk rekreasi, pelepasan energi, dan juga untuk memperoleh kepuasaan.

Kriteria layanan bantuan terdiri dari tiga jenis, yaitu kriteria layanan bantuan mandiri, kriteria layanan bantuan minimal, dan kriteria layanan bantuan maksimal. Kriteria layanan bantuan mandiri berarti siswa hanya memerlukan arahan dari guru, siswa hanya mendengarkan apa yang diperintahkan oleh guru yang nantinya siswa tersebut dapat melakukannya sendiri. Kriteria layanan bantuan minimal yaitu dimana guru harus memberikan contoh, instruksi, dan motivasi kepada siswa agar mau melakukan gerak. Kriteria layanan bantuan maksimal yaitu kriteria yang diberikan dengan dorongan, arahan, instruksi, dan 
motivasi maksimal dari guru mata pelajaran, guru kelas, maupun orang tua ikut turun tangan membantu.

Permainan melompat dalam atletik tidak berarti menghilangkan unsur keseriusan, mengabaikan unsur ketangkasan atau menghilangkan substansi pokok materi atletik. Akan tetapi permainan lompat jauh dalam atletik berisikan seperangkat gerak dasar maupun teknik dasar lompat jauh dalam atletik yang disajikan dalam bentuk permainan yang bervariasi dengan memperkaya perbendaharaan gerak dasar anak-anak (Bahagia, 2005).

Berdasarkan landasan teori dan kerangka berpikir yang telah diuraikan di atas, maka dapat dirumuskan hipotesis sebagai berikut. (1) ada perbedaan pengaruh metode pembelajaran bermain dan metode konvensional untuk meningkatkan gerak dasar lompat jauh gaya jongkok siswa tunagrahita ringan; (2) ada perbedaan pengaruh kriteria layanan bantuan mandiri dan layanan bantuan minimal untuk meningkatkan gerak dasar lompat jauh gaya jongkok siswa tunagrahita ringan; (3) terdapat interaksi antara metode pembelajarandan kriteria layanan bantuan untuk meningkatkan gerak dasar lompat jauh gaya jongkok siswa tunagrahita ringan.

\section{B. METODE PENELITIAN}

Penelitian ini merupakan penelitian eksperimen dengan rancangan penelitian faktorial $2 \times 2$ seperti tabel 1 .

Tabel 1. Rancangan Penelitian

\begin{tabular}{lcc}
\hline Metode Pembelajaran & \multicolumn{2}{c}{ Kriteria Layanan Bantuan $(\mathbf{B})$} \\
\cline { 2 - 3 }$(\mathbf{A})$ & Mandiri $\left(\mathrm{B}_{1}\right)$ & Minimal $\left(\mathrm{B}_{2}\right)$ \\
\hline bermain $\left(\mathrm{A}_{1}\right)$ & $\mathrm{A}_{1} \mathrm{~B}_{1}$ & $\mathrm{~A}_{1} \mathrm{~B}_{2}$ \\
Konvensional $\left(\mathrm{A}_{2}\right)$ & $\mathrm{A}_{2} \mathrm{~B}_{1}$ & $\mathrm{~A}_{2} \mathrm{~B}_{2}$ \\
\hline
\end{tabular}

Variabel penelitian yaitu: (1) variabel bebas, terdiri dari variabel bebas manipulatif dan variabel bebas atributif. Variabel manipulatif yaitu metode pembelajaran bermain dan konvensional. Variabel bebas atributif (yang dikendalikan) dalam penelitian ini yaitu siswa dengan layanan bantuan mandiri 
dan minimal; (2) variabel terikat (dependent), yaitu gerak dasar lompat jauh gaya jongkok.

Instrumen yang digunakan penelitian ini adalah: (1) penilaian kriteria layanan bantuan, (2) tes keterampilan gerak dasar lompat jauh gaya jongkok (pretes dan post-tes). Untuk menguji hipótesis penelitian, data yang diperoleh di tes akhir passing control dianalisis menggunakananalisis varian (ANAVA) pada taraf kepercayaan 95\% dilanjutkan dengan uji rentang hewman-keuls (Sudjana, 2004).

\section{HASIL PENELITIAN DAN PEMBAHASAN}

Uji normalitas data dalam penelitian ini digunakan Kolmogorov Smirnov berbantuan program SPSS 16.00. Dinyatakan bahwa data berdistribusi normal apabila nilai signifikansi $>0,05$. Hasil uji normalitas data dapat dilihat pada tabel 2 sebagai berikut.

Tabel 2 Hasil Uji Normalitas Data

\begin{tabular}{cccc}
\hline Data & Kolomoorov Smirnov Z & Sign & Keterangan \\
\hline Pre-tes & 0,718 & $0,680>0,05$ & Normal \\
Pos-tes & 0,879 & $0,423>0,05$ & Normal \\
\hline
\end{tabular}

Tabel 2 memperlihatkan bahwa nilai signifikansi dari data gerak dasar lompat jauh gaya jongkokuntuk data Pre-test 0,680 dan untuk data Post-test sebesar 0,423. Nilai signifikansi dari masing-masing data melebihi nilai 0,05 yang berarti bahwa data berdistribusi normal.

Uji homogenitas pada penelitian ini dilakukan dengan uji Levene Uji homogenitas dimaksudkan untuk menguji kesamaan varians antara kelompok sampel 1 dengan kelompok sampel 2. Hasil uji homogenitas data antara kelompok sampel 1 dan kelompok sampel 2 adalah sebagai berikut.

Tabel 3. Hasil Uji Homogenitas

\begin{tabular}{|c|c|c|c|}
\hline $\mathbf{F}$ & df1 & df 2 & Sig. \\
\hline 1.115 & 3 & 16 & .372 \\
\hline
\end{tabular}

Dari hasil uji homogenitas diperoleh nilaiF $_{\text {hitung }}=1.115$ dengan nilai signifikansi 1.115>0,05 yang berarti bahwa varians data antara kelompok tidak berbeda nyata atau bersifat homogen. 
Pengujian hipotesis penelitian dilakukan berdasarkan hasil analisis data dan interaksi analisis varians. Untuk mengetahui perbedaan perlu uji Anava, hasil ringkasan Anava menunjukkan adanya perbedaan yang signifikan.

Tabel 4 Ringkasan Anava Dua Faktor

\begin{tabular}{|l|r|r|r|r|r|}
\hline \multicolumn{1}{|c|}{ Source } & $\begin{array}{c}\text { Type III Sum } \\
\text { of Squares }\end{array}$ & Df & $\begin{array}{c}\text { Mean } \\
\text { Square }\end{array}$ & \multicolumn{1}{c|}{ F } & Sig. \\
\hline Corrected Model & 35.400 & 3 & 11.800 & 5.619 & .008 \\
MetodePembelajaran & 5445.000 & 1 & 5445.000 & $2.593 \mathrm{E} 3$ & .000 \\
Layanan Bantuan & 12.800 & 1 & 12.800 & 6.095 & .025 \\
MetodePembelajaran * & 9.800 & 1 & 9.800 & 4.667 & .046 \\
Layanan Bantuan & 12.800 & 1 & 12.800 & 6.178 & .025 \\
Error & 33.600 & 16 & 2.100 & & \\
Total & 5514.000 & 20 & & & \\
Corrected Total & 69.000 & 19 & & & \\
\hline
\end{tabular}

a. $\mathrm{R}$ Squared $=.730$ (Adjusted R Squared $=.422$ )

\section{PEMBAHASAN}

Hipotesis 1 yang menyatakan ada perbedaan pengaruh antara metode pembelajaran bermain dan metode konvensionaluntuk meningkatkan gerak dasar lompat jauh gaya jongkok siswa tunagrahita ringan pada pembelajaran penjasorkes SLB PKK Bandar Lampungdiuji menggunakan uji anava dan diperolehF $_{\text {hitung }}=6.095$ dengan nilai signifikansi 0,025 . Hasil perhitungan ini kemudian dikonsultasikan dengan tabel $\mathrm{F}$ dengan $\mathrm{dk}_{\text {pembilang }}=3$ dan $\mathrm{dk}_{\text {penyebut }}=$ 16, dan taraf signifikansi 0,05 diperoleh $\mathrm{F}_{\text {tabel }}=3,24$ karena $\mathrm{F}_{\text {hitung }}>\mathrm{F}_{\text {tabel }}$ atau 6,095> 3,24 dan nilai signifikansi $0,025<0,05$ maka $H_{0}$ ditolak, $H_{a}$ diterima. $\mathrm{H}_{\mathrm{a}}$ yang berbunyi : "Ada perbedaan pengaruh antara metode pembelajaran bermain dan konvensionaluntuk meningkatkan gerak dasar lompat jauh gaya jongkok siswa tunagrahita ringan". diterima. Dilihat dari hasil nilai rata-rata post-test menunjukan bahwa metode bermain memberikan pengaruh yang lebih baik untukpeningkatan gerak dasar lompat jauh gaya jongkok siswa tunagrahita ringan dibandingkan metode konvensional. 
Hipotesis 2 yang menyatakan ada perbedaan pengaruh antara siswa yang memiliki kriteria bantuan mandiri dan kriteria bantuan minimaluntuk meningkatkan gerak dasar lompat jauh gaya jongkok, siswa kelas IV SLB PKK Bandar Lampung diuji menggunakan uji anava dan diperoleh $F_{h i t u n g}=$ 4.667dengan nilai signifikansi 0,046. Hasil perhitungan ini kemudian dikonsultasikan dengan tabel $\mathrm{F}$ dengan $\mathrm{dk}_{\text {pembilang }}=3 \mathrm{dan} \mathrm{dk}_{\text {penyebut }}=16$, dan taraf signifikansi 0,05 diperoleh $\mathrm{F}_{\text {tabel }}=3,24$ karena $\mathrm{F}_{\text {hitung }}>\mathrm{F}_{\text {tabel }}$ atau 4.667>3,24 dan nilai signifikansi $0,046<0,05$ maka $\mathrm{H}_{0}$ ditolak, $\mathrm{H}_{\mathrm{a}}$ diterima. $\mathrm{H}_{\mathrm{a}}$ yang berbunyi : "ada perbedaan pengaruh yang signifikan antara kriteria bantuan mandiri dan kriteria bantuan minimal untuk meningkatkan gerak dasar lompat jauh gaya jongkok siswa tunagrahita ringan".diterima. Dengan demikian siswa dengan kriteria bantuan mandiri berperan dalam meningkatkan gerak dasar lompat jauh gaya jongkok dibandingkan dengan siswa dengan kriteria bantuan minimal.

Untuk menguji yang menyatakan terdapat interaksi antara metode pembelajaran dan kriteria layanan bantuandalam meningkatkan gerak dasar lompat jauh gaya jongkok siswa tunagrahita ringan digunakan uji anava, diperoleh $\mathrm{F}_{\text {hitung }}=6.095$ dengan nilai signifikansi 0.025 . Hasil perhitungan ini kemudian dikonsultasikan dengan tabel $\mathrm{F}$ dengan $\mathrm{dk}_{\text {pembilang }}=3 \mathrm{dan} \mathrm{dk}_{\text {penyebut }}=16$, dan taraf signifikansi 0,05 diperoleh $F_{\text {tabel }}=3,24$, karena $F_{\text {hitung }}>F_{\text {tabel }}$ atau 6.095 $>3,24$ dan nilai signifikansi $0.025<0,05$ maka $\mathrm{H}_{0}$ ditolak, $\mathrm{H}_{\mathrm{a}}$ diterima. $\mathrm{H}_{\mathrm{a}}$ yang berbunyi :" Terdapat interaksi antara metode pembelajaran dan kriteria layanan bantuan dalam meningkatkan gerak dasar lompat jauh gaya jongkok siswa tunagrahita ringan".diterima.

Selanjutnya diadakan analisis lanjut dengan uji tukey untuk mengetahui sejauh mana perbedaan interaksi masing-masingkelompok perlakuan.Hasil perhitungan dapat dirangkum pada tabel 5 .

Tabel 5.Perbedaan Interaksi Masing-masing Kelompok Perlakuan Menggunakan Uji Tukey

\begin{tabular}{cccc}
\hline Kelompok yang Dibandingkan & $\mathbf{Q}_{\text {hit }}$ & $\mathbf{Q}_{\text {tabel }}$ & Keterangan \\
\hline $\mathrm{A} 1 \mathrm{~B} 1><\mathrm{A} 1 \mathrm{~B} 2$ & $-10,801$ & 3,81 & Tidak berbeda \\
$\mathrm{A} 1 \mathrm{~B} 1><\mathrm{A} 2 \mathrm{~B} 1$ & $-6,172$ & 3,81 & Tidak berbeda \\
$\mathrm{A} 1 \mathrm{~B} 1><\mathrm{A} 2 \mathrm{~B} 2$ & 10,801 & 3,81 & Berbeda \\
\hline
\end{tabular}




\begin{tabular}{cccc}
\hline $\mathrm{A} 1 \mathrm{~B} 2><\mathrm{A} 2 \mathrm{~B} 1$ & 4,629 & 3,81 & Berbeda \\
$\mathrm{A} 1 \mathrm{~B} 2><\mathrm{A} 2 \mathrm{~B} 2$ & 21,602 & 3,81 & Berbeda \\
$\mathrm{A} 2 \mathrm{~B} 1><\mathrm{A} 2 \mathrm{~B} 2$ & 16,973 & 3,81 & Berbeda \\
\hline
\end{tabular}

Tabel 5 menunjukan bahwa hampir semua kelompok yang dibandingkan memiliki perbedaan atas hasil uji tukey.Ada dua kelompok yang tidak memiliki perbedaan, yaitu kelompok A1B1 dengan A1B2 dan A1B1 dengan A2B1. Sedangkan kelompok-kelompok yang memiliki perbedaan, yaitu kelompok A1B1 dengan A2B2, A1B2 dengan A2B1, A1B2 dengan A2B2, A2B1 dengan A2B2 .Perbedaan tersebut diketahui dari skor $\mathrm{q}$ hitung yang lebih besar daripada $\mathrm{q}$ tabel. Dimana $\mathrm{q}_{\text {hitung }}$ untuk kelompok A1B1 dengan A1B2 yaitu $-10,801<\mathrm{q}$ tabel 3,81 ,

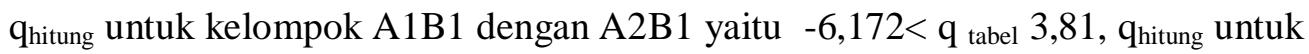
kelompok A1B1 dengan A2B2 yaitu 10,801> q tabel 3,81, $\mathrm{q}_{\text {hitung }}$ untuk kelompok A1B2 dengan A2B1 yaitu 4,629> $\mathrm{q}_{\text {tabel }} 3,81$, dan $\mathrm{q}_{\text {hitung }}$ untuk kelompok A1B2 dengan A2B2, yaitu 21,602> $\mathrm{q}$ tebel 3,81, sedangkan untuk kelompok A2B1 dengan $\mathrm{A} 2 \mathrm{~B} 2 \mathrm{q}$ hitung $16,973>\mathrm{q}$ tabel.

\section{KESIMPULAN}

Berdasarkan hasil analisis dan pembahasan tersebut di atas, maka dapat disimpulkan sebagai berikut: (1) adaperbedaan pengaruh metode pembelajaran bermain dan metode konvensional untuk meningkatkan gerak dasar lompat jauh gaya jongkok siswa tunagrahita ringan pada pembelajaran penjasorkes SLB PKK Bandar Lampung. Hasil pembelajaran gerak dasar lompat jauh gaya jongkok siswa yang menggunakan metode bermain lebih baik dibandingkan dengan siswa yang menggunakan metode konvensional.(2) adaperbedaan pengaruh yang signifikan antara kriteria bantuan mandiri dan kriteria bantuan minimal untuk meningkatkan gerak dasar lompat jauh gaya jongkok siswa tunagrahita ringan pada pembelajaran penjasorkes SLB PKK Bandar Lampung. Hasil pembelajaran gerak dasar lompat jauh gaya jongkok siswa dengan kriteria bantuan mandiri lebih baik dibandingkan dengan kriteria bantuan minimal. (3) terdapat interaksi antara metode pembelajaran pembelajaran dan kriteria layanan bantuan dalam 
meningkatkan gerak dasar lompat jauh gaya jongkok pada pembelajaran penjasorkes.

\section{DAFTAR PUSTAKA}

Adang Suherman dan Agus Mahendra.(2001). Menuju Perkembangan Menyeluruh. Jakarta: Dirjen Pendidikan Dasar dan Menengah. Dirjen Olahraga.

Apriyanto, Nunung. (2014). Seluk-Beluk Tunagrahita dan Strategi Pembelajarannya.Jogjakarrta : Javalitera, 2014.

Bahagia, Yoyo. (2010). Pembelajaran Atletik. Direktorat Jenderal Pendidikan Luar Biasa.

Dapan dan P. Eddy.(2011). Dasar-Dasar Gerak Atletik. Yogyakarta: Alfamedia.

Rusli, Lutan. (2000). Strategi Belajar Mengajar Penjaskes. Jakarta: Depdiknas. Dirjen Pendidikan Dasar dan Menengah.

Djamarah, Syaiful Bahri dan Aswan Zain.(2006). Strategi Belajar Mengajar. Jakarta: PT Rineka Cipta.

Husdarta dan Yudha M. Saputra.(2000). Belajar dan Pembelajaran. Jakarta: departemen Pendidikan Nasional. Dirjen Pendidikan Dasar dan Menengah.

Kurniasih.(2012). Kumpulan Permainan Interakstif untuk meningkatkan Kecerdasan Anak.Jogjakarta: Cakrawala. 